\title{
Reported Occurrences of Pacific Salmon in the Canadian Arctic Continue to Increase Whereas Reports of Atlantic Salmon Sightings Remain Low
}

\author{
Karen M. Dunmall ${ }^{1}$, Darcy G. McNicholl ${ }^{1}$, Ed Farley ${ }^{2}$, and James D. Reist ${ }^{1}$ \\ ${ }^{1}$ Fisheries and Oceans Canada, 501 University Cr., Winnipeg, Manitoba, Canada, R3T 2N6 \\ ${ }^{2}$ NOAA Fisheries, 17109 Point Lena Loop Rd., Juneau, Alaska, USA
}

Keywords: Pacific salmon, Atlantic Salmon, Arctic, range extension, climate change, subsistence fisheries

Environmental changes are affecting Pacific and Atlantic salmon production throughout their entire ranges (IUCN 2009; Grant et al. 2019). Warming water temperatures are influencing survival and abundances of salmon in freshwater habitats and are shifting optimal marine habitats northward (Abdul-Aziz et al. 2011; Yoon et al. 2015; Grant et al. 2019). Relatively high abundances of juvenile pink (Oncorhynchus gorbuscha) and chum

(Oncorhynchus keta) salmon were caught in the Chukchi Sea in 2007 (Eisner et al. 2013) and immature chum salmon were found at higher latitudes in the Bering Sea in 2009 (Sato et al. 2012). Catches of larger juvenile pink salmon in a warmer Chukchi Sea suggest that the sub-Arctic marine environment may be becoming viable salmon habitat (Moss et al. 2009). Atlantic salmon may also be shifting their marine distribution northward with warming temperatures (Todd et al. 2011; Chittenden et al. 2013). In freshwater, warming temperatures may also be improving pink salmon production in rivers flowing into the northern Bering Sea (Farley et al. 2020). Further north, there has been a sharp increase in the geospatial and temporal distributions of vagrant adult Pacific salmon in the Canadian Arctic in recent years (Dunmall et al. 2013, 2018), and increases in Pacific salmon have also been observed along the Alaskan north slope (Carothers et al. 2019) and in Greenland (Nielsen et al. 2020). Vagrant Atlantic salmon (Salmo salar) are occasionally harvested in subsistence fisheries in Nunavut (Bilous and Dunmall 2020) and are expected to shift northward, possibly impacting southern populations of Arctic Char (Salvelinus alpinus) due to overlaps in tolerances and habitat requirements (Reist et al. 2006; Jonsson and Jonsson 2009; Bilous and Dunmall 2020). Beyond indicating changes in production and distributions in their current ranges, Pacific and Atlantic salmon are also reminding us of the connections among our oceans.

In the Canadian Arctic, salmon are increasingly harvested in subsistence fisheries targeting preferred Arctic fishes. Arctic Salmon is a community-based monitoring program that tracks the occurrences of salmon harvests and other unusual fishes in subsistence fisheries across the Canadian Arctic. Through this program, it is possible to detect and monitor widening geographic occurrences and increasing abundance trends of rare species in a vast, remote, and sparsely populated environment (Dunmall et al. 2013,2018). Here, the objective is to update observed changes in Pacific salmon occurrence and harvest locations in subsistence harvests in the Canadian Arctic since previous reviews (Stephenson 2006; Nielsen et al. 2013; Dunmall et al. 2013, 2018), and relate these to a recent review of Atlantic salmon harvests in the Canadian Arctic (Bilous and Dunmall 2020). Reports of Pacific salmon harvested from 2018 to 2020, and provided to Fisheries and Oceans Canada through Arctic Salmon, are summarized by species and compared to previous reports of salmon from 2000 to 2017 (Dunmall et al. 2013, 2018), thus providing a 20-year record of salmon harvests in the Canadian Arctic. By continuing to document changing salmon distributions as a tangible example of biodiversity change, we can better understand the influence of rapid environmental change on Arctic ecosystems and its potential impact on cultures of northern Indigenous Peoples.

While following a generally increasing trend over the past 20 years, Pacific salmon harvests are becoming more variable in recent years in the Canadian Arctic, with the occasional years of extremely high harvests becoming more frequent and more extreme. Chum salmon remains the most abundant Pacific salmon species harvested across the Canadian Arctic, and is the only species harvested in the Mackenzie River consistently year after year. From 2016 to 2020 , three years $(2016,2017$, and 2019) have been documented with exceptionally high Chum Salmon harvests compared to only one year (2011) in the period 2010-2015. The number of salmon that may be present during these exceptional years also appears to be increasing (Fig. 1). Pink salmon harvests have shifted in recent years from higher harvests in even-numbered years to higher harvests in odd-numbered years (Fig. 1). Also, the geographic distribution of pink salmon harvests is increasing as they have now been reported in new locations, including near Cambridge Bay and Clyde River, Nunavut (McNicholl et al. in press), and upstream in the Mackenzie River to Fort Good Hope, Northwest Territories (Dunmall et al. unpublished data). Reported harvests of sockeye salmon have increased in recent years, from almost none prior to 2017 to over 400 in 2019, although harvests remain variable year to year (Fig. 1). Most of the sockeye salmon harvested in 2019 were caught in Sachs Harbour and Ulukhaktok, Northwest Territories. The number of Chinook salmon reported was variable from 2018 to 2020, from a low of zero to a high of 20 (Fig. 1). One coho salmon was reported harvested in the Canadian Arctic

All correspondence should be addressed to K. Dunmall. 
in 2019. The geographic distribution of chum, sockeye, Chinook, and coho salmon harvests did not expand from previous accounts (Dunmall et al. 2018).

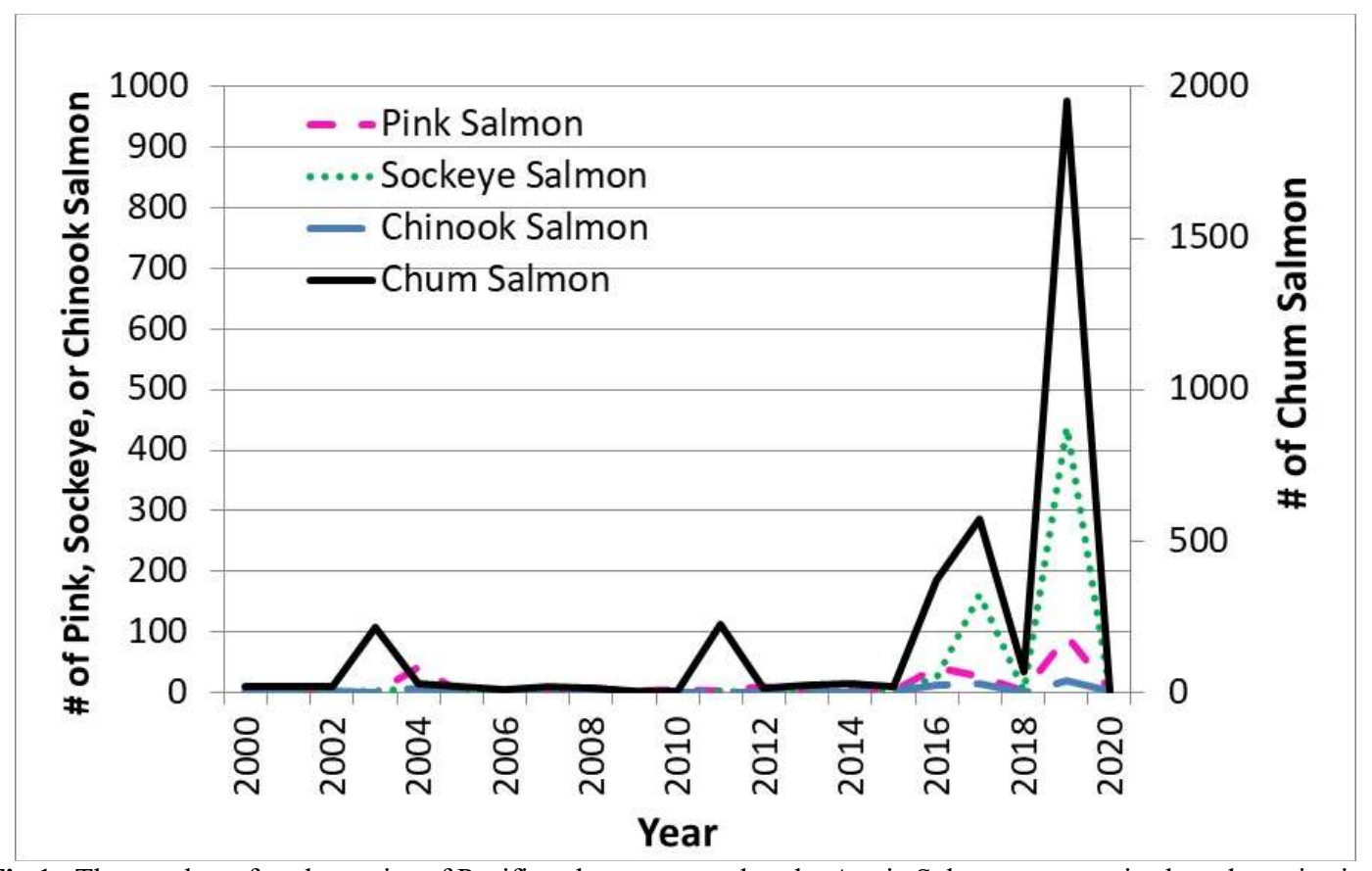

Fig 1. The number of each species of Pacific salmon reported to the Arctic Salmon community-based monitoring program from harvesters across the Canadian Arctic from 2000-2020. Only two coho salmon were reported during this period (in 2011 and 2019), thus they are not included.

Atlantic salmon harvests in the Canadian Arctic have been reported, although rarely, in 11 communities across Nunavut (reviewed in Bilous and Dunmall 2020). These sightings were summarized from Atlantic salmon occurrences and locations documented in Nunavut Coastal Resource Inventory (NCRI) reports (see https://www.gov.nu.ca/economic-development-and-transportation/information/nunavut-coastal-resource-inventory). These reports contain information obtained from interviews, maps, reports, research, and other resources and were completed by the Fisheries and Sealing Division of the Department of Environment (DOE), Government of Nunavut, in communities across Nunavut from 2007 to 2015. The information was intended to support assessment, management, and conservation opportunities, preserve Inuit Qaujimajatuqangit (IQ), and assist in preparing for environmental changes, particularly those that are induced by climate change (Government of Nunavut 2014). Most of the reported sightings were during summer months along the coast as well as in rivers and lakes; however, Atlantic salmon have also been occasionally sighted in freshwater during winter (Bilous and Dunmall 2020). Clyde River had the most reported sightings of Atlantic salmon $(n=14)$ compared to the other communities. While Pond Inlet reported the earliest harvests, in the 1950s, a specific timeframe for the Atlantic salmon observations in each community was only reported occasionally. As IQ is holistic and often based on a long time series of observations (Wenzel 2004), it is possible that sightings in other communities similarly span a long timeframe.

In conclusion, over the past 20 years, and particularly since 2011, almost all Pacific salmon species found in North America, with the exception of coho salmon, have increased in occurrence and geographic distribution in the Canadian Arctic. These species are also experiencing more extreme variations in harvests, with an increased frequency of exceptionally high harvests and a higher level of harvest during those exceptional years. A similar relative increase in occurrence, geographic spread, or extreme variation in harvests levels of Atlantic salmon in Nunavut has not been reported. While the difference in Pacific and Atlantic salmon harvests could be attributed to reporting frequency, the sharp contrast and consistency across almost all the communities in the Canadian Arctic suggests that there may be less Atlantic salmon than Pacific salmon species in coastal and freshwater environments in the Canadian Arctic. As distributions of Pacific and Atlantic salmon species are predicted to shift northward with environmental change (Reist et al. 2006; Abdul-Aziz et al. 2011; Todd et al. 2011; Chittenden et al. 2013), this difference in observations among species is an area for further investigation and could provide insight into the factors influencing northward distributional shifts in the marine environment. Within the reported Pacific salmon harvests, the extremes in variation and increases in salmon observed in recent years may be attributed in part to 
differences in reporting frequency across years. It is also possible that fishing conditions influenced harvests of salmon, and salmon may have been present in low-level harvest years but were not harvested due to poor fishing conditions (Chila et al. in press). However, consistency in reports of an increasing trend in Pacific salmon across communities in the western Canadian Arctic suggests that more salmon have been present in the western Canadian Arctic in recent years. Also, Inuvialuit knowledge about Pacific salmon harvests across the six communities in the Inuvialuit Settlement Region similarly document an increasing trend of Pacific salmon harvested in subsistence fisheries, attributed to climate change (Chila et al. in press). Therefore, the trends suggest that the occurrences of chum, pink, sockeye, and Chinook salmon are generally increasing and becoming more variable in the Canadian Arctic. Sightings of Atlantic salmon in the eastern Canadian Arctic occur but are not new and this species may not be experiencing similar dramatic trends.

The Arctic Salmon community-based monitoring program has expanded in recent years from an original focus on the Northwest Territories to also include communities across Nunavut in order to facilitate the detection of Pacific and Atlantic salmon in subsistence fisheries across the Canadian Arctic. The Arctic Salmon program has also shifted from monitoring salmon to monitoring the harvest and/or occurrence of all "unusual fish" across the Canadian Arctic, which also include other species found outside known distributions (McNicholl et al. in press). By developing a network of people interested in biodiversity change of fish across the Canadian Arctic, the Arctic Salmon program can connect individual sightings of usual harvests into a community-based monitoring program that effectively tracks changes in the biodiversity of fishes harvested in coastal and freshwater subsistence fisheries across a vast and remote area.

\section{REFERENCES}

Abdul-Aziz, O.I., N.J. Mantua, and K.W. Myers. 2011. Potential climate change impacts on thermal habitats of Pacific salmon (Oncorhynchus spp.) in the North Pacific Ocean and adjacent seas. Can. J. Fish. Aquat. Sci. 68: 1660-1680. doi: 10.1139/f2011-079.

Bilous, M., and K. Dunmall. 2020. Atlantic salmon in the Canadian Arctic: potential dispersal, establishment, and interaction with Arctic char. Rev. Fish Biol. Fish. 30: 463-483. doi: 10.1007/s11160-020-09610-2.

Carothers, C., T.L. Sformo, S. Cotton, J.C. George, and P.A.H. Westley. 2019. Pacific salmon in the rapidly changing arctic: Exploring local knowledge and emerging fisheries in Utqiagivik and Nuiqsut, Alaska. Arctic 72(3): 273-288.

Chila, Z.C.E., K. Dunmall, T. Proverbs, T. Lantz, Aklavik Hunters and Trappers Committee, Inuvik Hunters and Trappers Committee, Olokhaktomiut Hunters and Trappers Committee, Paulatuk Hunters and Trappers Committee, and Sachs Harbour Hunters and Trappers Committee. In press. Inuvialuit Knowledge of Pacific Salmon Range Expansion in the Western Canadian Arctic. Can. J. Fish. Aquat. Sci.

Chittenden, C.M., P. Fauchald, and A.H. Rikardsen. 2013. Important open-ocean areas for northern Atlantic salmon (Salmo salar) — as estimated using a simple ambient-temperature approach. Can. J. Fish. Aquat. Sci. 70(1): 101-104.

Dunmall, K.M., D.G. McNicholl, and J.D. Reist. 2018. Community-based monitoring demonstrates increasing occurrences and abundances of Pacific salmon in the Canadian Arctic from 2000 to 2017. N. Pac. Anadr. Fish Comm. Tech. Rep. 11: 87-90. doi: 10.23849/npafctr11/87.90.

Dunmall, K.M., J.D. Reist, E.C. Carmack, J.A. Babaluk, M.P. Heide-Jørgensen, and M.F. Docker. 2013. Pacific salmon in the Arctic: harbingers of recent great changes. In Responses of Arctic marine ecosystems to climate change. Edited by F.J. Mueter, D.M.S. Dickson, H.P. Huntington, J.R. Irvine, E.A. Logerwell, S.A. MacLean, L.T. Quakenbush, and C. Rosa. Alaska Sea Grant, Univ. Alaska Fairbanks. pp. 141-163. doi: 10.4027/ramecc.2013.07.

Eisner, L., N. Hillgruber, E. Martinson, and J. Maselko. 2013. Pelagic fish and zooplankton species assemblages in relation to water mass characteristics in the northern Bering and southeast Chukchi seas. Polar Biol. 36: 87113. doi: 10.1007/s00300-012-1241-0.

Farley, E., J. Murphy, K. Cieciel, K. Howard, E. Yasumiishi, K. Dunmall, T. Sformo, and P. Rand. 2020. Response of Pink salmon to climate warming in the northern Bering Sea. Deep-Sea Res. II 177. doi: 10.1016/j.dsr2.2020.104830.

Government of Nunavut. 2014. Nunavut coastal resource inventory-Clyde River. Department of Environment, Fisheries and Sealing Division, Iqaluit, Nunavut. (Available at https://www.gov.nu.ca/sites/default/files/ncri_clyde_river_en.pdf)

Grant, S.C.H., B.L. MacDonald, and M.L. Winston. 2019. State of Canadian Pacific Salmon: responses to changing climate and habitats. Can. Tech. Rep. Fish. Aquat. Sci. No. 3332. 50 pp. 
IUCN. 2009. Salmon and climate change; fish in hot water. Species Survival Commission. The IUCN Red List of Threatened Species. (Available at https://www.iucn.org/sites/dev/files/import/downloads/fact_sheet_red_list_salmon_v2.pdf)

Jonsson, B., and N. Jonsson. 2009. A review of the likely effects of climate change on anadromous Atlantic salmon Salmo salar and brown trout Salmo trutta, with particular reference to water temperature and flow. J. Fish Biol. 75(10): 2381-2447.

McNicholl, D.G., L. Harris, T. Loewen, P. May, L. Tran, R. Akeeagok, K. Methuen, C. Lewis, R. Jeppesen, S. Illasiak, B. Green, J. Koovaluk, Z. Annahatak, J. Kapakatoak, N. Kaosoni, B. Hainnu, B. Maksagak, J.D. Reist, and K.M. Dunmall. In press. Noteworthy occurrences among six marine species documented with community engagement in the Canadian Arctic. Animal Migrations. Special Issue: Arctic Migrations.

Moss, J.H., J.M. Murphy, E.V. Farley, L.B. Eisner, and A.G. Andrews. 2009. Juvenile pink and chum salmon distribution, diet, and growth in the northern Bering and Chukchi seas. N. Pac. Anadr. Fish Comm. Bull. 5: 191-196. (Available at https://npafc.org)

Nielsen, J.L., G.T. Ruggerone, and C.E. Zimmerman. 2013. Adaptive strategies and life history characteristics in a warming climate: salmon in the Arctic? Environ. Biol. Fish. 96: 1187-1226. doi: 10.1007/s10641-012-00826.

Nielsen, J., A. Rosing-Asvid, L. Meire, and R. Nygaard. 2020. Widespread occurrence of pink salmon (Oncorhynchus gorbuscha) throughout Greenland coastal waters. J. Fish Biol. 96(6): 1505-1507. doi: $10.1111 / \mathrm{jfb} .14318$.

Reist, J.D., F.J. Wrona, T.D. Prowse, M. Power, J.B. Dempson, J.R. King, and R.J. Beamish. 2006. An overview of effects of climate change on selected Arctic freshwater and anadromous fishes. Ambio 35(7): 381-387.

Sato, S., M. Kato, K. Morita, and S. Urawa. 2012. Stock-specific summertime distribution of immature chum salmon in the Bering Sea as inferred from SNP markers. N. Pac. Anadr. Fish Comm. Tech. Rep. 8: 50-51. (Available at https://npafc.org)

Stephenson, S.A. 2006. A review of the occurrence of Pacific salmon (Oncorhynchus spp.) in the Canadian Western Arctic. Arctic 59(1): 37-46.

Todd, C.D., K.D. Friedland, J.C. MacLean, N. Hazon, and A.J. Jensen. 2011. Getting into hot water? Atlantic salmon responses to climate change in freshwater and marine environments. In Atlantic salmon ecology. Edited by Ø. Aas, A. Klemetsen, S. Einum, and J. Skurdal. Wiley, West Sussex. pp 409-443.

Wenzel, G.W. 2004. From TEK to IQ: Inuit Qaujimajatuqangit and Inuit cultural ecology. Arctic Anthropol. 41(2): 238-250.

Yoon, S., E. Watanabe, U. Hiromichi, and M.J. Kishi. 2015. Potential habitat for chum salmon (Oncorhynchus keta) in the Western Arctic based on a bioenergetics model coupled with a three-dimensional lower trophic ecosystem model. Prog. Oceanogr. 131: 146-158. doi: 10.1016/j.pocean.2014.12.009. 